\title{
Low-cost Modifications in the COVID-19 Screening Outpatient Department in a Tertiary Care Hospital in North India in the Rational Use of Personal Protective Equipment
}

\author{
Neeraj Singla ${ }^{1}$, Deba P Dhibar ${ }^{2}$, Vikas Suri $^{3}$, Navneet Sharma ${ }^{4}$
}

\begin{abstract}
In the COVID-19 pandemic, infection control measures in a hospital setting are mainly aimed to reduce transmission of COVID-19 among healthcare workers working both in the COVID-19/non-COVID-19 areas. These include complete source control (covering the nose and mouth with appropriate masks to contain respiratory secretions), early identification (by widespread testing), isolation of patients with suspected disease, the use of appropriate personal protective equipment (PPE) while caring for patients with COVID-19, and ensuring proper disinfection of biomedical waste as per the standard hospital guidelines. At our institute, the screening outpatient department (OPD) room was separated for patients by a roof to floor fully covered with transparent glass partition with aluminum borders (Fig. 1). Communication with patients was established with mike (microphones) and speakers placed on both sides of the interphase for better audibility. It was sanitized with $1 \%$ Na hypochlorite solution three times a day.

Keywords: COVID-19, Healthcare workers, Preventive health, Rationale.

Journal of Postgraduate Medicine, Education and Research (2021): 10.5005/jp-journals-10028-1433
\end{abstract}

Since its first detection in Wuhan, China, in December 2019, SARSCoV-2 has spread to over 210 countries, with the USA, Italy, Spain, France, England, Germany, and Iran being the worst affected. ${ }^{1}$ India has witnessed around 66 lakh confirmed cases with 102,000 deaths as of October 5, 2020.2,3 India has so far been successful in breaking the chain of the spread of virus infection primarily by nonpharmacological interventions (NPI) which include social distancing, multiphased lockdowns, making the wearing of masks mandatory at public places and frequent use of hand sanitizers. The demand for personal protective equipment (PPE) apart from healthcare workers ( $\mathrm{HCW}$ ) has also increased significantly for other frontline workers including police personal, sanitary workers, and social workers. In an early report of COVID-19 in 138 patients from China, it was estimated that $43 \%$ of HCW had acquired infection in the hospital setting. ${ }^{4}$ In Washington State, suboptimal use of infection control procedures contributed to the spread of infection to 81 residents, 34 staff members, and 14 visitors in one long-term care facility. ${ }^{5}$

At present, infection control measures in a hospital setting are mainly aimed to reduce transmission of COVID-19 among HCW working both in the COVID-19/non-COVID-19 areas. These include complete source control (covering the nose and mouth with appropriate masks to contain respiratory secretions), early identification (by widespread testing), isolation of patients with suspected disease, the use of appropriate PPE while caring for patients with COVID-19, and ensuring proper disinfection of biomedical waste as per the standard hospital guidelines.

The first portal of entry at our institute, Postgraduate Institute of Medical Education and Research (PGIMER), Chandigarh, is the Emergency. The screening outpatient department (OPD) for COVID19 patients was started in late February 2020. With the increase in patient number, the requirement of manpower constantly increased and at present, the screening staff is working in three shifts per day
${ }^{1-4}$ Department of Internal Medicine, Postgraduate Institute of Medical Education and Research, Chandigarh, India

Corresponding Author: Neeraj Singla, Department of Internal Medicine, Postgraduate Institute of Medical Education and Research, Chandigarh, India, Phone: +919646121641, e-mail: neerajsingladr@ gmail.com

How to cite this article: Singla N, Dhibar DP, Suri V, et al. Low-cost Modifications in the COVID-19 Screening Outpatient Department in a Tertiary Care Hospital in North India in the Rational Use of Personal Protective Equipment. J Postgrad Med Edu Res 2021;55(4):186-187.

Source of support: Nil

Conflict of interest: None

and each shift includes one junior resident, one senior resident, one hospital attendant along with one consultant. A total healthcare workforce of 12 per day is manning in the screening area. As per CDC guidelines, ${ }^{6}$ screening staff should wear full PPE and N-95 masks if they are not separated by a physical barrier. Keeping in mind the rationalization of PPE use, we devised a simple and cost-effective physical barrier to reduce transmission.

At our institute, the screening OPD room was separated from patients by a roof to floor fully covered transparent glass partition with aluminum borders (Fig. 1). Communication with patients was established with mike (microphones) and speakers placed on both sides of the interphase for better audibility. It was sanitized with $1 \%$ Na hypochlorite solution three times a day.

By doing this small modification, the need to wear PPE (surgical gown, pair of shoe covers, two pair of sterile gloves, N-95 masks, and protective goggles along with aprons) was reduced, with the screening staff wearing only triple-layer surgical masks and simple surgical gown.

(o) The Author(s). 2021 Open Access This article is distributed under the terms of the Creative Commons Attribution 4.0International License (https://creativecommons. org/licenses/by-nc/4.0/), which permits unrestricted use, distribution, and non-commercial reproduction in any medium, provided you give appropriate credit to the original author(s) and the source, provide a link to the Creative Commons license, and indicate if changes were made. The Creative Commons Public Domain Dedication waiver (http://creativecommons.org/publicdomain/zero/1.0/) applies to the data made available in this article, unless otherwise stated. 


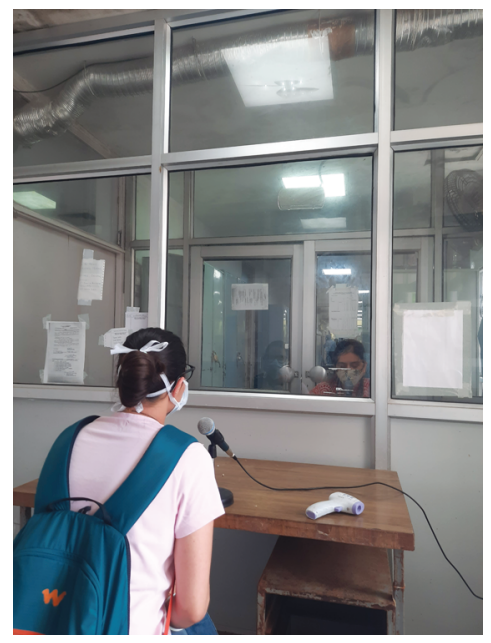

Fig. 1: Ceiling-to-floor glass partition in the COVID-19 screening OPD of PGIMER, Chandigarh, India

The total cost incurred on making this glass partition was $\$ 66$ (5,000 INR). The cost of each PPE kit is approximately $\$ 15$ to 19 (1,200-1,500 INR). Total PPE kits actually required for $12 \mathrm{HCW}$ posted in the screening area per day for 6 months would have been 2160 . Had we used PPE kits, the total expenditure incurred, would have been more than $\$ 34,000(2,497,640$ INR). So, we saved more than 2.5 million Rupees (INR). Moreover, to date, no HCW posted in the screening area has been affected.

Our institute has been declared a dedicated COVID hospital (DCH) by the Ministry of Health and Family Welfare, Govt. of India
(MOHFW). ${ }^{7}$ So, the huge amount of money saved, could be used in procuring essential life-saving pieces of equipment for the care of COVID-19 patients. Due to disruption of the global supply chain, WHO in its advisory, has called for optimizing the use of PPE as there is a severe shortage of PPE. ${ }^{8}$ In conclusion, to tackle this COVID-19 pandemic, judicious use of PPE is the need of the hour.

\section{References}

1. World Health Organization, Novel Coronavirus-China, January 12, 2020 (http://www.who.int/csr/don/12-january-2020-novel coronavirus-china/en/).

2. COVID-19 INDIA as on: 5 October 2020, 08:00 GMT+5:30; Available from https://www.mohfw.gov.in/.

3. Aarogya Setu App.

4. Wang D, Hu B, Hu C, et al. Clinical characteristics of 138 hospitalized patients with 2019 novel coronavirus-infected pneumonia in Wuhan, China. JAMA 2020;323(11):1061-1069. DOI: 10.1001/jama.2020.1585.

5. McMichael TM, Clark S, Pogosjans S, et al. COVID-19 in a long-term care facility - king county, Washington, February 27-March 9, 2020. MMWR Morb Mortal Wkly Rep 2020;69(12):339. DOI: 10.15585/mmwr. mm6912e1.

6. Centres for Disease Control \& Prevention COVID-19; Standard Operating Procedure (SOP) for Triage of Suspected COVID-19 Patients in non-US Healthcare Settings: Early Identification and Prevention of Transmission during Triage, April 15, 2020.

7. Ministry of Health \& Family Welfare Directorate General of Health Services EMR Division; Guidance document on appropriate management of suspect/confirmed cases of COVID-19: 7th April 2020.

8. Rational use of personal protective equipment for coronavirus disease (COVID-19) and considerations during severe shortage, Interim guidance; April 6, 2020. World Health Organization. 